\title{
SIMMEL E OS CAMINHOS PARA O DESENVOLVIMENTO DE UMA SOCIOLOGIA VITALISTA
}

\author{
Simmel and the roads for the development of a vitalist sociology
}

\author{
Gustavo Martins do Carmo Miranda'
}

\begin{abstract}
Resumo
Diante do constante interesse pelo vitalismo no pensamento sociológico atual, alguns escritores procuram resgatar e enfatizar o papel precursor de Georg Simmel (1858-1918) para o desenvolvimento de uma sociologia vitalista - a partir do início do século XX. Tendo em vista esta atenção recorrente dada ao autor alemão, este artigo procura aprofundar a relação entre o vitalismo e Simmel, no intuito de apresentar a construção do vitalismo sociológico por parte deste autor. Este trabalho está organizado em duas partes. Na primeira, será explanado o desenvolvimento da corrente vitalista na Alemanha - centrada em uma crítica epistemológica ao racionalismo moderno - no decorrer do século XIX. Na segunda parte, será inicialmente demonstrado como o vitalismo - do ponto de vista da epistemologia - contribuiu para que Simmel desenvolvesse um pensamento vitalista relacionado à sociologia do conhecimento. Posteriormente, será enfatizado como o autor - partindo da sociologia do conhecimento conectada ao vitalismo - compreendeu a dinâmica do ambiente social, bem como a modernidade.
\end{abstract}

Palavras-chave: Simmel; sociologia do conhecimento; vitalismo; racionalismo; epistemologia.

\begin{abstract}
Faced with the constant interest in vitalism in current sociological thinking, some writers seek to rescue and emphasize Georg Simmel's pioneering role (1858-1918) for the development of a vitalist sociology from the beginning of the twentieth century. In view of this recurrent attention given to the German author, this article seeks to deepen the relationship between vitalism and Simmel, in order to present the construction of sociological vitalism on the part of this author. This work is organized in two parts. In the first, the development of the vitalist current in Germany - centered on an epistemological critique of modern rationalism - will be explained in the course of the nineteenth century. In the second part, it will be shown how vitalism - from the point of view of epistemology - contributed to Simmel developing a vitalist thinking related to the sociology of knowledge. Subsequently, it will be emphasized how the author - starting from the sociology of knowledge connected to vitalism - understood the dynamics of the social environment as well as modernity.
\end{abstract}

Keyword: Simmel; Sociology of knowledge; vitalism; rationalism; epistemology.

\footnotetext{
1 Mestre em Sociologia pela Universidade Estadual de Campinas (UNICAMP). Email: gustavmcm@gmail.com
} 


\section{Introdução}

Atualmente, quando falamos no chamado vitalismo, podemos perceber o quanto é corriqueiro este termo nos estudos envolvendo áreas como: da computação; da biologia; da filosofia política; dos meios de informação e comunicação; e da cibernética (GRECO, 2005; LASH, 2006; PYYTNIEN, 2012).

Tendo em vista esta multiplicidade de áreas relacionadas ao vitalismo, não podemos deixar de destacar que a sociologia também se enquadra neste contexto. Na sociologia contemporânea ${ }^{2}$ (principalmente através dos estudos sobre globalização e da chamada "teoria ator-rede") $)^{3}$, é cada vez mais significativa a presença de um pensamento ligado à corrente vitalista (LASH, 2005; VANDENBERGHE, 2006).

Se atualmente muitos dos autores que procuram tratar do vitalismo são chamados de "neovitalistas" (LASH, 2006), isto significa que os sociólogos contemporâneos também buscam inspiração em escritores - ou correntes presentes na sociologia dita clássica. Daí o papel fundamental - e de certa forma pioneiro - de Georg Simmel, para o desenvolvimento de uma sociologia relacionada ao vitalismo no início do século XX.

Tendo sido influenciado pelo vitalismo a partir de 1900, Simmel manteve até 1918 - ano de seu falecimento - uma sólida relação com autores e ideias vitalistas. Tida como uma corrente caracterizada por uma atenção voltada totalmente para as "experiências da vida", alguns intelectuais chegaram a criticar o período que o autor esteve conectado ao vitalismo. Segundo Moraes Filho (1983), György Lukács (1885-1971) afirmou que na sua maturidade o escritor germânico apoiou-se em um vitalismo irracional, relativista e anticientífico.

Apesar das criticas, sociólogos contemporâneos procuram resgatar e enfatizar a importância de Simmel como o precursor de uma sociologia dita vitalista. De acordo com Scott Lash (2005), por exemplo, o autor germânico foi o pioneiro da chamada sociologia da vida (Lebenssoziologie).

\footnotetext{
2 Segundo Scott Lash (2005), a sociologia contemporânea - influenciada pelo vitalismo - evita a chamada causalidade externa das análises multivariáveis, para ceder lugar à autocausalidade. Ademais, a sociologia vitalista também se relaciona ao fenômeno da globalização.

3 Segundo os argumentos de Vandenberghe (2006), a "teoria ator-rede" reformula o problema da ordem social, incluindo nesta ordem os objetos como base que contém as relações sociais. Os humanos devem se associar aos não humanos para formar uma sociedade durável.
} 
Simmel e os caminhos para o desenvolvimento | Gustavo Martins do Carmo Miranda

Levando em consideração o crescente interesse da sociologia contemporânea pelo vitalismo, este trabalho procura apresentar as influências, as origens e o desenvolvimento do pensamento sociológico vitalista elaborado por Simmel no início do século XX.

Como método, optamos pela utilização do chamado contextualismo linguístico desenvolvido por Quentin Skinner (1996). Tal proposta busca analisar de forma ampla os trabalhos dos escritores, isto é, tanto os aspectos intelectuais, quanto os sociais que circundam uma determinada obra. Neste sentido, o contextualismo linguístico leva em consideração a relação - e não a disjunção - presente entre o autor, o texto e o contexto.

Como fontes bibliográficas principais, utilizaremos neste artigo os trabalhos de Simmel redigidos entre 1900-1918. Ademais, apoiamos em fontes secundárias de comentadores que procuraram compreender o período de produção intelectual simmeliana relacionado ao vitalismo.

$\mathrm{Na}$ primeira parte do artigo, apresentaremos do ponto de vista epistemológico as raízes da corrente vitalista - centrada na crítica ao racionalismo - realizada pelos poetas e filósofos germânicos do século XIX.

$\mathrm{Na}$ segunda parte deste trabalho, mostraremos inicialmente os caminhos do vitalismo para a teoria sociológica, através das chamadas ciências do "espírito". Em seguida demonstraremos o contato e as influências do vitalismo em Simmel. Posteriormente, destacaremos como o autor alemão construiu um pensamento sociológico vitalista influenciado por uma ótica voltada para a sociologia do conhecimento.

$\mathrm{Na}$ terceira parte, abordaremos como Simmel - a partir de uma sociologia do conhecimento influenciada pelo vitalismo - elaborou uma concepção micro e macro do meio social. Em seguida, apresentamos como esta concepção foi analisada pelo autor alemão no advento da modernidade.

\section{Do racionalismo ao vitalismo: uma crítica com bases epistemológicas}

A origem ou o desenvolvimento inicial do vitalismo é basicamente descrita através de dois movimentos pelo meio acadêmico atual. Um deles está relacionado ao posicionamento crítico que biólogos franceses e alemães (durante a virada do século XVIII para o século XIX), expressaram diante das 
pesquisas ligadas à vida. Para estes autores, era necessário compreender os fenômenos da vivência através de uma maneira oposta a uma tradição da química e da biologia (GRECO, 2005), que se conectava ao pensamento científico racionalista moderno vigente até então. “[...] os médicos vitalistas foram os principais antagonistas do modelo físiológico do corpo-máquina, tradição que passava de René Descartes [...] à iatromecânica [...]" (ALFONSOGOLDFARB; AMARAL; WAISSE, 2011, p. 636).

O segundo está conectado a um movimento heterogêneo (desenvolvido no decorrer do século XIX) composto basicamente por poetas e filósofos (em sua maior parte germânicos) críticos à abstração do racionalismo moderno bem como do Iluminismo. Este conjunto de autores compartilhava a necessidade de se compreender a vida enquanto uma espécie de "unidade" e “totalidade” (LASH, 1999; VANDENBRGHE, 2005; WAIZBORT, 2011a).

Embora neste trabalho seja dada uma atenção mais acentuada ao segundo movimento, é interessante notar que em ambos os casos o vitalismo é apresentando como uma crítica ao racionalismo moderno. Como discordância a este racionalismo, cabe destacar que há uma necessidade de aprofundar esta questão para o domínio da epistemologia, isto é, ao chamado estudo da filosofia que trata dos fundamentos do conhecimento de forma geral (SELL, 2010)4. Ao fazermos isto, deixamos a mera descrição de lado e compreenderemos as raízes de uma aversão - por parte dos vitalistas - ao racionalismo moderno, bem como a necessidade de um entendimento da "vida" propriamente dita - através de outro mecanismo de conhecimento.

Do ponto de vista de uma modernidade situada no processo de ruptura com os saberes ligados preponderantemente à religião ${ }^{5}$ - durante o período da Idade Média ocidental -, podemos afirmar que a partir do Renascimento surgido no século XV - ocorreu um descolamento do centro do conhecimento

\footnotetext{
4 Esta chamada "forma geral" do conhecimento pode ser conectada com as observações de Peter Berger e Thomas Luckmann. "[...] definir 'conhecimento' com a certeza de que os fenômenos são reais e possuem características específicas. É nesse sentido [...] que estes termos têm importância tanto para o homem da rua quanto para o filósofo" (BERGER; LUCKMANN, 2012, p. 13, grifo dos autores).

5 "Nos embates entre o saber sagrado e o conhecimento científico, este último emergia como hegemônico, alavancado no seu enraizamento na realidade empírica, na sua universalidade e, sobretudo, na legitimidade que lhe outorgava a sua paternidade sobre as mudanças tecnológicas” (CANO, 2012, p. 96).
} 
antes pautado em Deus (teocentrismo), para o homem (antropocentrismo) ${ }^{6}$. “Comparados a seus predecessores medievais, os membros das sociedades europeias a partir do 'Renascimento' ascenderam a um novo nivel de autoconsciência” (ELIAS, 1994a, p. 86, grifo do autor).

Este novo nível de autoconsciência, proporcionou a diminuição do grau de dependência dos indivíduos com as entidades até então reinantes - como a Igreja Católica. Daí o desejo de desvendar os fenômenos através da atividade do "ser pensante", isto é, do próprio sujeito - mediante estudos mais aprofundados. A chamada Revolução Científica - iniciada aproximadamente no século XVI - materializou este processo, e teve no nome de René Descartes (1586-1650) o grande expoente de uma epistemologia centrada no próprio individuo:

O problema básico da epistemologia correspondeu a essa forma de autoconsciência humana. Tomou como ponto de partida a condição absoluta conferida ao momento de autodesprendimento que faz parte do ato de cognição naquilo a que chamamos o estágio "cientifico" do desenvolvimento. Baseou-se na noção de um sujeito cognoscente em oposição ao mundo dos objetos cognosciveis, do qual ele seria separado por um vasto divisor (Ibidem, p. 92, grifo do autor).

O autodesprendimento do sujeito para a busca do conhecimento fez do observador (neste caso o próprio indivíduo) constatar os fenômenos de forma quase que independente. Daí a noção de um "pensar" baseado na capacidade do intelecto, ou seja, no que Descartes designou como "coisa pensante" (res cogitans).

Se o pensar estava relacionado ao intelecto, este último era basicamente denominado como razão, isto é, a capacidade racional inata presente no sujeito em desvendar os acontecimentos presentes em sua volta. Sem uma relação dita conectiva com os fenômenos a serem observados, estes últimos não exerciam um papel de interdependência diante da racionalidade do indivíduo. "Em sua condição de observado, o ser humano percebia-se como parte de um processo natural [...]" (Ibidem, p. 90). Na visão de autores como Descartes, este processo natural representava - por assim dizer - os acontecimentos externos, isto é, os fenômenos físicos - lineares. "Este era visto

\footnotetext{
6 "Tornaram-se cada vez mais capazes de se verem como que a distância, tomando o Sol por centro do universo, em vez de presumirem ingenuamente que a Terra, e portanto, eles próprios, eram esse centro. Essa 'revolução coperniana' foi extremamente característica do novo patamar de autoconsciência que essas pessoas, lentamente, atingiram" (ELIAS,1994a, p. 86, grifo do autor).
} 
como uma espécie de mecanismo de relógio ou máquina que, como outras coisas do mesmo tipo, era percebido pelos sentidos" (Ibidem, p. 90). Neste caso, era nesta linearidade dos fenômenos físicos que estava presente a figura do sujeito enquanto observado.

$\mathrm{Na}$ ausência de uma percepção para além desta linearidade presente nos fenômenos físicos, o sujeito - como observador - não conseguia situar sua real presença enquanto observado. "Tudo o que estava 'fora', fosse coisa ou ser humano, aproximava-se dele como que a posteriori, como algo desconhecido que se postasse sozinho diante do mundo - por exemplo, no caso do filósofo - como observador e pensador em busca da resposta a uma pergunta" (Ibidem, p. 95, grifos do autor).

O que se sucedeu ao desenvolvimento do racionalismo moderno - nos séculos seguintes do início da Revolução Científica - não modificou de forma acentuada o panorama do saber centrado na razão inata humana. Neste caso, ocorreu exatamente uma afirmação mais contundente deste fato. $\mathrm{O}$ surgimento do Iluminismo no século XVIII veio comprovar este prosseguimento. "O Iluminismo foi, antes de tudo, um movimento intelectual que tinha como objetivo entender e organizar a sociedade a partir da razão humana" (SELL, 2010, p. 16). A dificuldade do sujeito em se perceber enquanto observado - diante dos fenômenos físicos - parece que influenciou os iluministas, pois para Immanuel Kant (1724-1804)7, o Iluminismo “[...] levaria o homem a sua plena maturidade" (Ibidem, p. 16). Esta plena maturidade salientada por Kant pode ser traduzida como uma espécie de um nível pleno da razão humana alcançada no século das luzes, porém desprovida de uma determinada trajetória:

A questão era como uma pessoa "racional", uma pessoa com o aparato mental de um adulto, podia obter conhecimento do mundo. Para fins

\footnotetext{
7 Apesar deste fato, é importante destacar que Kant procurou equacionar o problema do conhecimento do sujeito (enquanto observador e observado). Mas tal esforço não obteve um êxito preciso. "Imaginou que, em nosso conhecimento do mundo, as experiências que nos chegam de fora através dos sentidos fundiam-se com formas de relações e ideias presentes em nossa consciência antes de qualquer experiência. E, ainda que a contribuição kantiana tenha representado um considerável refinamento da concepção das ideias inatas, as dificuldades elementares em que ela se deixou apanhar foram as mesmas. No fim, também Kant se viu confrontado com a questão de saber se realmente era possível conhecer as coisas em si, tais como eram, independentemente das formas preexistentes de consciência, ou se essas ideias e formas primárias de relação que existiam a priori e que segundo ele presumiu, eram atributos eternos e inalteráveis da consciência humana, condenavam permanentemente os seres humanos a perceberem os objetos como eles apareciam em decorrência desses atributos (ELIAS, 1994a, p. 94, grifo do autor).
} 
epistemológicos, abstraía-se a observação de que todo adulto um dia fora criança; isso era posto de lado como irrelevante para o problema de como se adquiria conhecimento. A questão era saber como um indivíduo racional e adulto podia, aqui e agora, obter conhecimento de coisas do lado de fora (ELIAS, 1994a, p. 95, grifo do autor).

Neste sentido, não seria errôneo afirmar que era basicamente no "aqui" e no "agora" que se situava o sujeito do conhecimento na visão de grande parte dos autores ligados ao Iluminismo. Por isto que em Kant, o conhecimento dito a priori (ou racional), funcionava como uma espécie de condição de possibilidade da experiência ${ }^{8}$. Não existia uma relação cronológica do saber e da experiência, mas sim lógica (VANDENBERGHE, 2005)9. "Eles costumam partir, como era de esperar, de uma específica e estabelecida auto-imagem que eles tomam como uma verdadeira e imutável imagem de homem" (ELIAS, 2008, p. 57).

Foi diante de uma contundente controvérsia a este racionalismo moderno, que o vitalismo se desenvolveu e ganhou notoriedade principalmente na Alemanha - durante o decorrer do século XIX. Contrários à sólida influência Iluminista que se alastrava no país germânico desde o ano de 1740 (NETTO, 2014) ${ }^{10}$, diversos intelectuais viam no Iluminismo - bem como na própria Revolução Francesa - um movimento que tendia a universalizar a razão. Este fato impossibilitava enxergar o particular, isto é, a peculiaridade dos acontecimentos.

Esta leitura crítica referente ao Iluminismo ganhou força primeiramente - através de poetas ligados ao movimento romântico alemão conhecido como "Tempestade e ímpeto" (Sturm and Drang). Autores como Johann Wolfgang von Goethe (1749-1832) e Johann Gottfried von Herder (1744-1803), fizeram parte deste grupo (REIS, 2003; VANDENBERGHE, [2001] 2005).

O que deve ser analisado de imediato - tomando como base os escritores românticos alemães - é que o deslocamento do universal ao particular foi

\footnotetext{
8 Kant procurou designar a posteoriori - ou empíricos - o conhecimento que provém da experiência (VANDENBERGHE, 2005).

9 É preciso enfatizar que Kant não negou a existência da realidade exterior. O que o filósofo germânico argumentou é que esta realidade não era conhecivel em si (REIS, 2003).

10 O Iluminismo triunfou no solo germânico no período da ascensão de Frederico - o Grande - na Prússia. Nesta época, o racionalismo moderno praticamente adquiriu todos os espaços possíveis no meio acadêmico da Alemanha (NETTO, 2014).
} 
desenvolvido diante de uma aproximação com a noção germânica de cultura (Kultur). Está última: "Reporta-se a produtos humanos ou são semelhantes a 'flores do campo', a obra de arte, livros, sistemas religiosos ou filosóficos, nos quais se expressa a individualidade de um povo. O conceito de Kultur delimita" (ELIAS, 1994b, pp. 25-26, grifo do autor).

Era neste conceito de cultura que o indivíduo - bem como a própria nação - estava situado mediante uma noção de criação e cultivação (Kultiviertheit), isto é, de um fazer humano. Os românticos alemães procuraram desenvolver em suas histórias uma conexão entre os personagens e a cultura:

Gradativamente, a atenção passou a se concentrar não apenas na narração dos acontecimentos, mas em como as pessoas os vivenciavam. Os autores descreviam uma paisagem, por exemplo, e ao mesmo tempo a chamada "paisagem interior", no sentido mais estrito ou mais amplo do termo - le pasage intérieur. Descreviam encontros entre as pessoas e, ao mesmo tempo, o "fluxo de consciência" delas ao se encontrarem (Idem, 1994a, p. 87, grifos do autor).

Os acontecimentos narrados passaram a ter uma plena conexão com o que as pessoas vivenciaram. Daí a ligação entre cultura e vida (Leben). O descolamento do sentido kantiano de unidade (Einheit) como uma sintese de componentes descontínuos e contingentes (VANDENBERGHE, 2005), para a base primordial da existência (Dasein) em Goethe, simbolizou o sentido da vida para os românticos alemães. Como uma unidade existencial, a vida11 passou a ser compreendida como um movimento totalizante de experiências ${ }^{12}$ vividas, que englobava principalmente: intuição; vontade; sentimento; impulso; criatividade; fluxo; liberdade; vigor; e dinamismo (LASH, 2006; VANDENBERGHE, 2005; WAIZBORT, 2000, 2011a).

Como uma unidade de existência, a difícil incompatibilidade de conexão entre o sujeito (enquanto observador e observado) da tradição racionalista moderna, parecia que acabou ganhando um novo patamar com os românticos:

Nessa percepção, a ênfase amiúde se desloca da "razão", como traço distintivo do eu "interior" separado do mundo "externo", para algo que [...] se baseia não apenas nas funções intelectuais, mas também nos

\footnotetext{
11 Através dos poetas e filósofos, a noção da vida desenvolveu-se através de duas referências: 1) concebida objetivamente (das Leben), não pressupondo um sujeito consciente; e 2) concebida subjetivamente (das Erleben), através de um sujeito consciente de sua "vida vivida" (VANDENBERGHE, 2005).

12 Experiência neste caso engloba a compreensão da vida por ela mesma (REIS, 2003).
} 
sentimentos, na "verdadeira natureza" da pessoa inteira [...] (ELIAS, 1994a, p. 107, grifos do autor).

No caso dos românticos, a separação cedeu lugar para uma junção entre o sujeito e os fenômenos externos. Tais fenômenos eram providos de conexão, pois faziam parte da vida enquanto uma unidade existencial. Não eram simplesmente fisicos, mas de vivência. Daí que o próprio escritor - ao contrário de uma figura isolada - também tinha sua vida interligada aos acontecimentos (LASH, 1999).

Seguindo o caminho traçado pelos românticos, os filósofos germânicos - precisamente a partir da segunda metade do século XIX - também conduziram seus pensamentos para o vitalismo, pois assimilavam - na maioria das vezes - a filosofia com a atividade poética (Ibidem). Daí o surgimento da chamada filosofia da vida (Lebensphilosophie). Arthur Schopenhauer (1788-1860), Friedrich Nietzsche (1844-1900) e Wilhelm Dilthey (1833-1911) foram alguns dos filósofos que fizeram parte deste grupo.

Em Nietzsche, por exemplo, a totalidade da vida foi concentrada através da noção de "poder". Tanto poder no sentido de potentia (energia fisica, vigor e força), como de potestas (possibilidade de fazer) (LASH, 2006). Já em Dilthey, a vida se relacionava a uma experiência existencial. "[...] o que interessa a Dilthey não é simplesmente a noção genérica de vida, mas sua unidade construtiva, a 'vivência'. Toda a experiência humana é formada por vivências [...]" (COHN, 2003, p. 23, grifo do autor). Em contraposição a uma tradição filosófica que afirmava ser a realidade exterior era uma mera representação, Dilthey argumentava que esta realidade nada mais era do que a própria vida em seu sentido amplo (WAIZBORT, 2011b).

A ideia da vida - como unidade - foi uma forma dos filósofos vitalistas se contraporem ao chamado dualismo filosófico presente tanto em Descartes, como posteriormente em Kant. Este dualismo polarizava a "mente" (composta pela substância ideal), da "matéria" (substância material). Daí a ideia de um monismo filosófico por parte dos autores ligados ao vitalismo (LASH, 2006).

\section{Da epistemologia à sociologia: Simmel, vitalismo e a sociologia do conhecimento}


Diante da crítica ao racionalismo moderno desenvolvido pelos vitalistas, surgiram - por assim dizer - as bases do vitalismo na sociologia. Daí a importância do entendimento da epistemologia centrada na unidade da vida, para o desenvolvimento posterior da teoria sociológica. Conforme salientou Sell (2010), a sociologia também é fundamentada em aspectos epistemológicos , isto é, possui princípios filosóficos que servem de alicerce e influência para a construção das teorias sociológicas.

Foi através das bases epistemológicas que a sociologia se desenvolveu através de dois princípios de pensamentos. Uma centrada no objeto (sociedade) e a outra no sujeito (indivíduo). A influência do vitalismo para o pensamento sociológico girou em torno da segunda corrente, em virtude das criticas de Dilthey às ciências naturais.

No decorrer do século XIX as ciências naturais (influenciadas pelo racionalismo moderno) apresentaram um desenvolvimento significativo. Este fato propiciou sua sólida influência no processo do advento das ciências sociais - iniciado a partir da segunda metade do século XIX ${ }^{13}$. Neste sentido, Dilthey - já nos finais do século XIX - destacou a necessidade de distinguir as ciências da natureza (Naturwissenchaften), das chamadas ciências do "espírito" (Geisteswissenschaften), ou ciências humanas. "[...] os caminhos de Dilthey nos levam a concluir que a epistemologia das ciências humanas [...] não pode ser meramente uma extensão de epistemologia das ciências naturais" (SCOCUGLIA, 2002, p. 268).

Parece que a linearidade dos fenômenos externos - enquanto físicos presente na tradição do racionalismo moderno, guiou o filósofo alemão na sua distinção entre as ciências da natureza e as ciências do "espírito". Para Dilthey, enquanto a primeira tinha como função principal explicar (Erklarën) os eventos observados na natureza, a segunda procurava compreender (Verstehen) a experiência vivida (Erlebniz). Nas ciências naturais não havia

\footnotetext{
13 "Ainda que com alguns prenúncios no século XVIII, é só no século XIX que este modelo de racionalidade se estende às ciências sociais emergentes. A partir de então pode falar-se de um modelo global de racionalidade científica que admite variedade interna mas que se distingue e defende, por via de fronteiras ostensivas e ostensivamente policiadas, de duas formas de conhecimento não-científico (e, portanto, irracional) potencialmente perturbadoras e intrusas: o senso comum e as chamadas humanidades ou estudos humanísticos (em que se incluíram, entre outros, os estudos históricos, filológicos, jurídicos, literários, filosóficos e teológicos)” (SANTOS, 1988, p. 48).
} 
Simmel e os caminhos para o desenvolvimento | Gustavo Martins do Carmo Miranda

uma aproximação concreta com o sujeito. Cabia às ciências do "espírito" desenvolver este fato em seu campo de estudo, priorizando assim a vida humana enquanto sujeito e objeto ao mesmo tempo.

Era na própria vida que o objeto de estudo das ciências humanas apresentava-se como imediatamente dado (LÖWY, 2003; SELL, 2010). A compreensão da experiência vivida contribuía para o "[...] processo de relação da experiência interna como um conjunto, envolvendo a experiência externa como um de seus aspectos" (SCOCUGLIA, 2002, p.270).

Se com os românticos alemães havia uma tendência em situar o próprio escritor nos acontecimentos presentes na chamada unidade da vivência, em Dilthey a ideia de compressão não se dirigia simplesmente "[...] a literalidade das palavras e seu sentido objetivo, mas também a individualidade de quem fala e, consequentemente, do autor" (Ibidem, p. 256).

O pensamento vitalista de Georg Simmel relacionado à sociologia desenvolveu-se diante da tradição sociológica centrada no sujeito (indivíduo). Foi em virtude da crítica perante as influências das ciências naturais durante o decorrer do século XVIII (SIMMEL, 1997a, 2007a), que o autor elaborou sua concepção de indivíduo. Neste sentido:

\begin{abstract}
Essa tendência foi sustentada por uma corrente histórica ainda mais profunda, pelo peculiar conceito de natureza presente no espírito daquele tempo. Os interesses teóricos do século XVIII estavam totalmente orientados para as ciências naturais. Continuando o trabalho do século XVII, instituíram o conceito de lei natural como o mais elevado ideal de conhecimento. Para este, porém, desaparece a individualidade autêntica e tudo o que há de incomparável e inalienável na existência individual. Aqui vigora somente a lei universal, e cada fenômeno, um ser humano ou uma mancha nebulosa na Via Láctea, não passa de um caso singular daquela lei, e, mesmo na total impossibilidade de repetir sua forma, é apenas um ponto de cruzamento e um conjunto solucionável de leis conceituais gerais. Ao menos era assim que se entendia então a "natureza" somente os poetas a compreendiam de outra maneira (Idem, 2006, p. 96 , grifo do autor).
\end{abstract}

A continuidade teórica de que falava Simmel, remetia basicamente ao racionalismo do século XVII. Foi justamente deste cenário que se construíram as bases para uma concepção genérica do indivíduo. Daí a ênfase da razão como preponderante. Segundo o autor, no século XVIII, isto só veio a intensificar, e Kant, foi um dos principais expoentes para este processo se consolidar. "Na filosofia de Kant o conceito de individualidade adquire a 
sublimação intelectual mais elevada" (Ibidem, p. 99). Este ápice intelectual simbolizava uma individualidade de cunho abstrato, isto é, desprovida de uma conectividade. Nas palavras de Simmel: "Visto que Kant e sua época tornam o homem abstrato, a individualidade, livre de todos os laços e determinações singulares, é sempre igual a si mesma, é a sublimação última da personalidade [...]" (Ibidem, pp. 99-100).

Esta individualidade completamente livre apontada por Simmel, só não afetou de fato os poetas - no final do século XVIII. Daí a influência do romantismo alemão. Para o autor, o trabalho de Goethe conhecido como Os anos de aprendizado de Wilhelm Mister (1795-1796), simbolizou uma forma de individualismo baseada na singularidade,isto é, na vida enquanto uma unidade. "[...] o interesse dos seres humanos se dirige à humanidade - não no sentido do homem abstrato que vimos predominar no século XVIII, e sim no sentido [...] da totalidade concreta do gênero vivo" (Ibidem, pp. 112-113). Foi nesta totalidade da vida, que Simmel identificou não o indivíduo puramente racional, mas sim o vital, ou seja, com suas emoções e inclinações para alguma coisa (VANDENBERGHE, 2005).

A noção da vida para os românticos germânicos estava direcionada a um ato (die Tat) (SIMMEL, 2007b). Tendo como base este fato, a ação segundo os argumentos de Simmel - não era propriamente "[...] fundida em uma universalidade abstrata da lei [...] ela encontra seus fundamentos e suas raízes na própria vida, [...] que é a vida de um indivíduo singular" (VANDENBERGHE, 2005, p. 191).

Simmel observou que os românticos deixaram um importante legado para os filósofos. De acordo com o autor, os românticos alemães acabaram influenciando ao longo do século XIX a ideia de uma individualidade como forma de vivência. "[...] esse Romantismo propiciou ao individualismo as bases do sentimento, da vivência. Os românticos foram os primeiros, depois de Herder [...] a ambientar-se na especificidade e na univocidade das realidades históricas [...]" (SIMMEL, 2006, p. 115). Guiados por esta ideia de vivência, Nietzsche e Schopenhauer, foram os expoentes da filosofia da vida neste período (Idem, 1997a). 
Simmel e os caminhos para o desenvolvimento | Gustavo Martins do Carmo Miranda

Os estudos centrados na totalidade da vida por parte dos filósofos vitalistas contribuíram para uma unidade que havia sido cindida pelo modelo preconizado pelas ciências naturais. Caracterizado inicialmente por uma polaridade entre sujeito e objeto no âmbito da natureza, tal pressuposto das ciências naturais se estendeu para os estudos sobre a sociedade no século XIX - neste caso para a própria sociologia (Idem, 2007b). Neste sentido, enquanto uma corrente reduzia o indivíduo a uma entidade hipotética - ou a um átomo - em meio a um ponto de intercessão de várias séries sociais, a outra tendia a considerar o homem como uma parte integradora - e com obrigações - em relação ao meio social (Idem, 1997a).

Através dos filósofos vitalistas foi possivel ter em mente a noção de um indivíduo da unidade (Eizigheit) ${ }^{14}$, em contraposição ao indivíduo da solidão (Einzelheit) ${ }^{15}$. Era a partir desta unidade presente no sujeito que se derivava por assim dizer - as formações sociais. Em Nietzsche, por exemplo, as “[...] instituições sociais, todo dar e receber por meio dos quais o indivíduo se torna um ser social, são somente condições prévias ou consequências de sua própria natureza" (Idem, 2006, p. 89). Segundo Simmel - cabia um esforço para aprofundar em que sentido - e de que maneira - a vida se desdobrava para algo além de si mesma. "Diferentemente da natureza, a sociedade não precisa de um observador externo para existir [...]" (VANDENBERGHE, 2005, p. 19). Daí a importância do autor para o entendimento da experiência da vida no âmbito social (gesellschaftliches Leben) (LASH, 2005).

De acordo com os argumentos de Simmel cabia às ciências do "espírito" - daí a influência de Dilthey - compreender que o indivíduo "[...] em toda a sua essência e em todas as suas expressões [...] vive interativamente com outros seres humanos [...]" (SIMMEL, 2006, p. 20). Nesta passagem, podemos observar o deslocamento do sentido de vivência para algo além da vida propriamente dita, isto é, para uma interindividualidade que remetia a uma possivel ideia de relação social. Segundo Vandenberghe (2005), a ideia de

\footnotetext{
14 Simmel não se apoiou em um individualismo metodológico de cálculo utilitário. Ele buscou se apoiar na natureza biográfica dos sujeitos, isto é, na unidade da pessoa (VANDENBERGHE, 1999).

15 "Para Nietzsche, é o ser qualitativo da personalidade que marca o estágio atingido pelo desenvolvimento de nossa espécie, pois, com seus exemplares respectivamente mais elevados, a humanidade supera seu passado" (SIMMEL, 2006, p. 90, grifo do autor).
} 
conhecimento em Simmel tinha como base primordial as profundezas da vida (pulsões, emoções e criações contínuas), experimentadas de maneira imediata e denominadas como "máximo da vida" (Mehr-Leben). Com o tempo, está última ultrapassava os limites da vida propriamente dita e transformava-se na chamada "vida mais que vida" (Mehr als Leben).

Quando Simmel enfatizou a necessidade de compreender a vida do ponto de vista de "uma produção social", não podemos deixar de destacar que havia neste argumento uma visão sociológica voltada para uma localização das ideias. "O ponto de vista da produção social [...] produzem na relação recíproca dos seres humanos, ou por vezes são também elas mesmas relações recíprocas, mas de uma maneira tal que não podem ser deduzidas do indivíduo observado em si mesmo" (SIMMEL, 2006, p. 21). Daí uma possível influência da chamada sociologia do conhecimento ${ }^{16}$ em seu pensamento vitalista. Tendo como influência intelectual que remonta ao pensamento de autores germânicos - ligados ao vitalismo - como Nietzsche e Dilthey (BERGER,1980), a sociologia do conhecimento procura traçar uma forma de relacionar as ideias para além do domínio propriamente lógico ou racional (ELIAS, 2008). Neste sentido, tal ramo da sociologia:

[...] trata da localização social das ideias [...] a sociologia do conhecimento elucida o que se quer dizer ao afirmar que o sociólogo é o homem que pergunta a todo instante: "Quem disse?" Ele rejeita a ideia de que o pensamento ocorra isolado do contexto social dentro do qual determinados homens pensam sobre determinadas coisas. Mesmo que no caso de ideias muito abstratas que aparentemente têm pouquíssima conexão social, a sociologia do conhecimento tenta traçar a linha que une o pensamento, seu autor e o mundo social deste (BERGER, 1980, p. 125, grifo do autor).

Se na tradição das ciências do "espírito", o objeto de estudo partia da experiência imediatamente vivida, isto quer dizer que no pensamento vitalista de Simmel relacionado à sociologia do conhecimento, a vida do sociólogo estava imersa no objeto de estudo. O próprio autor utilizava muito do recurso do ensaio (Versuch) ${ }^{17}$ em seus textos, para simbolizar sua presença ${ }^{18}$ na

\footnotetext{
16 "O termo foi usado pela primeira vez na década de 20 pelo filósofo alemão Max Scheler. Outro pensador, Karl Mannheim, que passou os últimos anos de sua vida na Inglaterra foi um dos que despertaram a atenção do pensamento anglo saxônico para a nova disciplina” (BERGER, 1980, p. 124). 17 O ensaio se desenvolveu de maneira sólida através do surgimento dos jornais e periódicos na Inglaterra no século XVIII. Tem como característica fundamental em sua forma de escrita, a estrutura circular de argumentação, isto é, tende à repetição (WAIZBORT, 2000).

18 "Por detrás do ensaio encontramos, sempre, seu autor: Georg Simmel" (Ibidem, p. 73).
} 
Simmel e os caminhos para o desenvolvimento | Gustavo Martins do Carmo Miranda

escrita. "Na constelação do ensaio persevera o sujeito. O ensaio está ligado à subjetividade. Está ligado à concepção/visão de mundo de quem o escreve" (WAIZBORT, 2000, p. 69).

Era da subjetividade presente no ensaio que Simmel procurou demonstrar como se desenvolvia a vivência. "Por essa razão, ele tenta circunscrever estes dois momentos: a experiência do sujeito e o seu experimentar" (Ibidem, p. 69). Daí a possível localização da vida do pesquisador em relação a outras vivências, isto é, em um ambiente de relação social. Parafraseando Löwy (2003), Simmel nos faz perceber que cada cientista social tenta pintar um quadro da realidade. Mesmo que este quadro da realidade possuísse pontos de vistas distintos por parte dos pesquisadores, isto é, perspectivas diferentes, as visões destes últimos formariam - no final das contas - uma teia de inter-relação. Através de um exemplo ligado aos estudos históricos, Simmel buscou elucidar este fato:

O historiador da política e da história geral da cultura atualmente sente-se inclinado, de várias maneiras, a deduzir, por exemplo, o caráter da política interna e das leis de um país a partir de causas suficientes dos processos econômicos correspondentes. Suponha que ele tenha explicado o forte individualismo da constituição política da primeira fase da Renascença italiana com base na liberação das relações econômicas de suas amarras canônicas e corporativas. A contribuição de um historiador da arte pode ser valiosa para qualificar essa concepção. O historiador da arte constata, já no início da época em questão, a monstruosa disseminação de retratos em forma de bustos e seu caráter individual e naturalista (SIMMEL, 2006, p. 24).

Nesta passagem relacionada a um exemplo sobre dois historiadores, podemos perceber que Simmel procurou destacar a presença da particularidade de ambos na pesquisa, isto é, seus pontos de vistas próprios em relação ao estudo sobre a individualidade no Renascimento. Porém, isto não significava que ambas as interpretações estavam desconectadas e isoladas:

\footnotetext{
$\mathrm{Na}$ verdade, o conhecimento precisa ser compreendido segundo um princípio estrutural totalmente diferente, segundo um princípio que, partindo do complexo de fenômenos que aparentemente constitui uma unidade, dele retire um grande número de variados objetos do conhecimento específicos - com especificidades que não impeçam o reconhecimento desses objetos de maneira definitiva e unitária (Ibidem, p. 25).
}

Neste sentido, mesmo que houvesse dois pontos de vistas distintos a respeito da individualidade desenvolvida no Renascimento, o que se pode 
observar é justamente um complemento dos argumentos apresentados a respeito deste processo. "O conhecimento se instaura através de um jogo de relações entre proposições, das quais nenhuma, considerada isoladamente, pretenderia ser absolutamente verdadeira" (VANDENBERGHE, 2005, pp. 222223). Daí a ideia de um princípio a nível relacional ${ }^{19}$ que rejeitava uma única causa como fator preponderante.

Como um princípio relacional, as interpretações de ambos os historiadores indicariam pontos de vistas marcados por um processo, isto é, um fluxo que passaria por uma determinada trajetória - que devia ser levada em consideração. De acordo com os argumentos de Simmel:

Essa descoberta indica que o individualismo econômico observado era já a expressão de uma mudança sociológica fundamental, que encontrou sua configuração no campo da arte, assim como da política, sem que uma fosse a causa imediata da outra (SIMMEL, 2006, p. 25).

Através do exemplo sobre os historiadores, parecia que Simmel buscou utilizar esta questão para resgatar um fato sociológico relacionado ao vitalismo no próprio período do Renascimento. Era como se ele quisesse demonstrar que os historiadores estavam inseridos dentro da época renascentista. Isto indica que a localização das ideias para o autor alemão - além de possuir um caráter de interação interindividual - também designava uma espécie de transmissão a nivel geracional. Mediante a tradição (Überlieferung) (HULAC, 2012), as gerações perpassavam sobre a vida dos indivíduos de forma concreta. "[...] o ser humano social, diferentemente de toda vida subumana, não é somente descendente, mas sobretudo herdeiro" (SIMMEL, 2006, p. 21). Daí a impressão que no advento do Renascimento, havia se instaurado as bases do saber epistêmico vitalista.

O uso dos exemplos dos historiadores era basicamente uma maneira de Simmel demonstrar que a tradição estava relacionada à história (Geschichte) $^{20}$. Daí a importância desta última como um mecanismo de

\footnotetext{
19 “[...] pleiteando uma multiplicação de perspectivas e de formulações de conteúdos da experiência que se completam, mais do que se opõem, Simmel desenvolve uma teoria do conhecimento na qual a verdade é múltipla e relacional" (VANDENBERGHE, 2005 pp. 53-54). Para Leopoldo Waizbort (2000), Simmel partia de uma concepção relativista do conhecimento. Porém, isto não indicaria puramente um relativismo, mas sim um processo relacional.

20 É importante destacar que atrás desta concepção, também estava uma crítica de Simmel ao materialismo histórico (WAIZBORT, 2000). "Essas analogias sociológicas nos permitem chegar a uma concepção que supera o materialismo histórico e que é mais profunda que ele: talvez as mudanças históricas, de acordo com sua camada realmente ativa, sejam transformações sociológicas; talvez
} 
Simmel e os caminhos para o desenvolvimento | Gustavo Martins do Carmo Miranda

conhecimento existencial (SAIEDI, 1987), e que possibilitava tornar o passado uma realidade inteiramente ativa (HULAC, 2012). Como bem salientou Elias (2008), o conhecimento deve ser tratado como um processo que supere a duração da vida do indivíduo - bem como de suas próprias descobertas.

\section{Do nível micro ao nível macro: a tensão na vida moderna sob a ótica de um vitalista situado no seu tempo}

O que se pode constatar é que pelas vias da sociologia do conhecimento, Simmel acabou relacionando tal ramo da sociologia com seu pensamento vitalista. Este fato possibilitou a localização das ideias tanto no sentido micro (interindividual), como no macro (as tradições).

Se no sentido micro havia uma tentativa de inserção da própria vida do pesquisador e de demais pesquisadores - o que gerava um processo de interação entre os diferentes pontos de vistas -, isto quer dizer que a vida do indivíduo - de forma geral - também não estava de fora deste processo. De acordo com Simmel, a chamada sociação (Vergesellschaftungen) era um processo caracterizado basicamente pela interação (Wechselwirkung) dos conteúdos vitais (como a arte, o direito, a técnica, a religião, a moral, o trabalho, o costume, o sentimento e as funções relacionadas à inteligência) originado do processo de formação (Bildung) ${ }^{21}$ da cultura subjetiva de cada sujeito (SIMMEL,1998). Neste sentido, quando a cultura se exteriorizava de maneira objetiva (Entaüberung), ocorria propriamente o processo de sociação.

Formada por pontos de vistas distintos, a interação entre as ideias dos pesquisadores não indicava simplesmente uma relação amena, pois havia um ambiente de divergências de opiniões. Daí o fato de que para Simmel, a sociação também era um espaço de tensão presente entre a vida dos individuos. Neste sentido, harmonia e desarmonia compunham os dois pilares da constituição do processo de sociação.

Como um processo dinâmico, a sociação indicava para Simmel apenas o primeiro estágio de interação presente entre a vida dos indivíduos. Daí a

\footnotetext{
interfiram no modo como os indivíduos se comportam em relação aos outros; como os indivíduos se comporta em relação ao grupo; como as ênfases nos valores, as acumulações, as prerrogativas e fenômenos semelhantes se movem entre os elementos sociais" (SIMMEL, 2006, p. 25).

21 A formação (Bildung) indica algo relacionado à personalidade, isto é, a algo individual (WAIZBORT, 2000).
} 
presença da história, e com isto o deslocamento para uma relação a nível macro. Segundo o autor alemão, a sociação se transformava em sociabilidade (Geselligkeiti), isto é, em relações mais complexas dos conteúdos vitais desenvolvidos pelos sujeitos. "[...] o 'impulso de sociabilidade' [...] se desvencilha das realidades da vida social e do mero processo de sociação como valor e como felicidade, e constitui assim o que chamamos de 'sociabilidade' [...] em sentido rigoroso" (Idem, 2006, p. 64, grifo do autor).

Em decorrência do desenvolvimento da sociabilidade, os conteúdos vitais começavam a se desprender de sua origem criadora vital, para adquirir um aspecto mais robusto, coeso e sólido. Diante disto, a consolidação das chamadas formas, isto é, da cultura objetiva. "[...] damos a estes materiais determinadas formas [...] essas forças e esses interesses se liberam, de um modo peculiar, do serviço à vida que os havia gerado e aos quais estavam originalmente presos. Tornam-se autônomos [...]" (Ibidem, p. 61).

A objetivação (Objektivierung) presente nas formas simbolizava a própria institucionalização dos conteúdos vitais originados dos indivíduos. Daí o caráter sólido - por exemplo - da religião, da ciência e das leis. Apesar deste fato, as formas possuiam uma historicidade, em virtude do seu processo de construção ao longo de um determinado período (Idem, 1997a). "As formações de que Simmel fala constituíram-se no curso da história, e isso garante ao conceito de cultura uma dimensão histórica que lhe é essencial" (WAIZBORT, 2000, p. 117).

Era da historicidade presente nas formas, que se preservava a conexão entre a cultura subjetiva e a cultura objetiva. Se com os pesquisadores, a tradição funcionava como uma espécie de reconhecimento existencial das gerações perpassadas historicamente, isto quer dizer que as formas não possuíam uma independência em relação à vida dos indivíduos. Era como se através da cultura objetiva, os sujeitos alcançassem uma espécie de subjetivação da cultura (Erinnerung), isto é, um aperfeiçoamento de suas próprias vidas (SIMMEL, 1997b).

Através do processo de subjetivação, a transmissão histórica a nível geracional não impedia a presença da singularidade dos indivíduos. Este fato possibilitava tanto a manutenção da interação (sociação), quanto o 
prevalecimento da construção dos conteúdos vitais. Mesmo que assumissem um caráter rígido, as formas objetivas funcionavam como um meio ${ }^{22}$ para os sujeitos - que eram propriamente os fins (Ibidem). Daí o papel protagonista da vida dos indivíduos para a renovação das formas.

O mesmo ambiente de harmonia e desarmonia encontrado na relação micro, isto é, na sociação, também se apresentava nas formas objetivadas. Daí que uma espécie de tensão similarmente estava presente nestas últimas, em virtude de sua relação de oposição perante a vida (VANDENBERGHE, 2005). Entretanto, com a intensificação do progresso da modernidade, os elementos que compunham a cultura objetiva adquiriam cada vez mais uma autonomia. Isto impedia a subjetivação da cultura por parte da vida dos indivíduos. Este fato propiciava uma ruptura tanto da relação micro, como da relação macro, isto é, das interações a nivel interindividual e histórico. Era como se as formas se tornassem fins em si mesmo, e com isto se distanciassem dos sujeitos. "A vida em sua criatividade produz continuamente algo que já não incorpora mais vida [...] algo que se impõem a vida com suas próprias exigências distintas" (SIMMEL, 1916, p. 41 apud LEVINE, 2015, p.40).

A possível guinada à sociologia do conhecimento - ligada ao vitalismo propiciou Simmel se localizar e vivenciar um período conturbado, que simbolizava talvez o ápice das consequências das objetivações das formas na modernidade. "Sua teoria do moderno é o seu enfrentamento com a cidade que vivia, suas próprias experiências formam o material que atiça a sua reflexão e a tentativa de apreender conceitualmente as transformações que ocorrem" (WAIZBORT, 2000, p. 315).

Em 1914, a Primeira Guerra Mundial eclodiu, e era neste ambiente em virtude da participação alemã no conflito beligerante - que Simmel presenciou o desfecho de uma ruptura crucial entre vidas e formas. Mesmo que a guerra simbolizasse uma ação sem reconhecimento por parte dos indivíduos, foi em meio a esta própria batalha que o autor identificou os possiveis impulsos vitais oriundos dos germânicos. Isto possibilitava uma ruptura diante das formas preponderantes, mediante um reconhecimento

22 "[...] a vida tem necessidade da forma para se exprimir, mesmo quando a forma tende a abafar a expressão da vida" (VANDENBERGHE, 2005, p. 169). 
existencial independente das mesmas (SIMMEL, 1997a). Conforme destacou Donald Levine (2015), no ensaio conhecido como "A transformação interior da Alemanha" (Deutschlands innere Wandlung, 1914), Simmel dizia que o advento da guerra promovia uma espécie de união orgânica entre os indivíduos e a sociedade alemã. Este fato proporcionava aos germânicos adquirirem naquele momento - tanto uma realidade espiritual elevada, quanto uma manifestação mais profunda das possibilidades da vida humana. Neste sentido, poderiamos dizer que o viés nacionalista dirigido a Simmel por parte de alguns autores (VANDENBERGHE, 2005), estava associado à sociologia do conhecimento - com influências vitalistas - desenvolvida pelo escritor.

Apesar destes argumentos em torno da primeira guerra, Simmel enfatizou o caráter efêmero do impulso vital por parte dos alemães. Isto quer dizer que tal acontecimento se verificava no momento do conflito, mas posteriormente não se sustentava. Daí um desdobramento originado das objetivações desenfreadas das formas. Como estas últimas perdiam o contato com os indivíduos, não ocorria o processo de subjetivação da cultura - e consequentemente a reformulação das culturas objetivas. “[...] Em 1918 [...] Simmel retrata o dilema central da cultura moderna não como opressão do eu subjetivo pelas formas multiplicadas da cultura objetiva, mas como ataque à própria possibilidade de formas objetivas por meio da liberação da expressão crua de energias vitais dos sujeitos" (LEVINE, 2015, p. 40). Era como se o indivíduo da unidade se tornasse um individuo da solidão. Diante deste fato alguns movimentos - europeus - surgidos no período da primeira guerra (como o Expressionismo nas artes, o Pragmatismo na filosofia e um certo misticismo na religião), careciam de uma relação com as formas já existentes (SIMMEL, 1997a). Neste sentido, pensando novamente em uma sociologia do conhecimento relacionada ao vitalismo, podemos indicar a dificuldade do próprio pesquisador - neste caso Simmel - em perceber a história como um reconhecimento existencial naquele momento.

\section{Considerações Finais}

Segundo os apontamentos de Leopoldo Waizbort (2000), vários rótulos são atribuídos a Simmel. Dentre eles, está justamente o vitalismo presente em 
seu pensamento. Neste artigo não foi proposto classificar o autor de vitalista, por isso o uso da palavra "caminhos" - no plural - encontrada logo no título deste trabalho. Caminhos indicam possiveis direções, e foi isso o que tentamos mostrar, pois devemos lembrar que Simmel foi heterogêneo em seu desenvolvimento teórico construído em vida.

Para desvendar os caminhos, é preciso partir de uma rota inicial. Por isso, o esforço neste artigo em procurar esclarecer primeiramente as raízes epistemológicas do vitalismo - centrada na crítica ao racionalismo moderno. Este fato possibilitou depararmos com um movimento conduzido principalmente por poetas e filósofos alemães - ao longo do século XIX - que relacionava a vida - enquanto uma totalidade - com a cultura - enquanto cultivo e criação. Tal movimento foi de suma importância para entendermos o contato e o desenvolvimento do vitalismo sociológico simmeliano. Como bem salientou Vandenberghe (2005), Simmel - dentre os chamados pais fundadores da sociologia - foi certamente o mais filosófico, pois sua sociologia era fundamentada em sólidas premissas epistemológicas.

Se a sociologia de Simmel tinha como fundamento a epistemologia fica evidente encontrar, a partir de 1900, a construção de sua sociologia vitalista. A virada do século XIX para o século XX foi o momento de transição da juventude para a fase de maturidade da intelectualidade do autor. Este fato representou uma modificação de sua visão sociológica.

A juventude de Simmel foi marcada por uma visão científica da sociologia. Este fato fez o autor desenvolver seus trabalhos iniciais através de um modo sistemático de apresentação. Tal sistematicidade consistia na aversão ao ensaio e na ênfase ao tratado, isto é, em uma tentativa de delimitar a sociologia como uma nova ciência (WAIZBORT, 2000). Daí o esforço deste artigo em concentrar o foco nas análises dos textos simmelianos escritos desde1900. Foi a partir desta data que o ensaio - enquanto um estilo de escrita - se manteve solidamente presente em seus trabalhos. "Os temas dos ensaios são por definição absolutamente livres" (Ibidem, p. 48).

Nos argumentos discutidos ao longo do artigo, conseguimos notar que a corrente vitalista trazia a ideia da presença do autor na escrita, isto é, suas próprias vivências. Por isso, nossa intenção em observar que a chamada 
sociologia do conhecimento - relacionada à procura da localização das ideias - estaria associada ao caráter ensaísta de Simmel - e, portanto, ao seu pensamento vitalista. Recordando os argumentos de Vandenberghe (2005), o escritor germânico possuía uma espécie de questionamento epistemológico sobre as condições de possibilidade do conhecimento sociológico.

Se Simmel tinha o interesse sobre as condições de possibilidade do conhecimento sociológico, este fato se relacionava com sua capacidade de enxergar no ensaio a inviabilidade de uma verdade absoluta (WAIZBORT, 2000). Daí a existência de outras vivências no ambiente social presenciada por distintos pesquisadores que formariam, no final das contas, um ambiente marcado pelas relações de perspectivas no meio social. A partir destas relações, Simmel enxergou o processo de transformação da vida em formas da cultura subjetiva em cultura objetiva. "No centro do ensaio está a relação do indivíduo com a cultura, do indivíduo com suas objetivações" (Ibidem, p. 48).

Por último, vale apena destacar - ainda na esteira da virada do século XIX para o século XX - a relação entre vida, formas e história - por parte de Simmel. Até o final da Primeira Guerra Mundial, a temática da filosofia da história era frequentemente discutida no meio universitário alemão. Esta temática teve influência significativa em Simmel a partir do início do século XX, através das leituras aprofundadas da discussão efetuada por Dilthey em relação à diferença entre as ciências históricas e as ciências naturais (SCOCUGLIA, 2002; WAIZBORT, 2000).

As ciências históricas eram basicamente as ciências do "espírito" ou sociais que abordamos ao longo deste artigo. Situado em um contexto alemão marcado tanto pelo acentuado processo de urbanização, como pelo advento traumatizante da primeira guerra, Simmel expressou no seu estilo ensaístico - sem rigidez quanto à sistematicidade - o ambiente de constante transformação da vida social. Daí a tensão na modernidade envolvendo o processo de desenvolvimento, transformação e reconhecimento da relação entre vida e formas - construído ao longo da história. Neste sentido, não interessaria simplesmente ao autor entender cientificamente a história, pois era necessário situá-la na dinâmica da vivência presente na sociedade. 


\section{Referências}

ALFONSO-GOLDFARB, Ana M; AMARAL, Maria Thereza Cera Galvão do; WAISSE, Silvia. Raízes do vitalismo francês: Bordeu e Barthez, entre Paris e Montpellier. Manguinhos: História, Ciências, Saúde, v. 18, n. 3, 2011.

BERGER, Peter L. Perspectivas sociológicas: uma visão humanística. 5. ed. Petrópolis: Vozes, 1980.

BERGER, Peter L.; LUCKMANN, Thomas. A construção social da realidade: tratado de sociologia do conhecimento. 13. ed. Petrópolis: Vozes, 2012.

CANO, Ignacio. Nas trincheiras do método: o ensino da metodologia das ciências sociais no Brasil. Porto Alegre, Sociologias, v. 14, n. 31, 2012.

COHN, Gabriel. Critica e Resignação. Fundamentos da Sociologia de Max Weber. São Paulo: Martins Fontes, 2003.

ELIAS, Norbert. A sociedade dos individuos. Rio de Janeiro: Jorge Zahar, $1994 a$.

O processo civilizador. Rio de Janeiro: Jorge Zahar, 1994 b.

. Sociologia do conhecimento: novas perspectivas. Brasília, Sociedade

e Estado, v. 23, n. 3, 2008.

FILHO, Evaristo de Moraes. Formalismo sociológico e teoria do conflito. In: FILHO, Evaristo de Moraes (org.). Georg Simmel: sociologia. São Paulo, SP: Ática, 1983.

GRECO, Monica. On the vitality of vitalism [Online]. London, Theory, Culture \& Society, v. 22, n. 1, 2005.

HULAC, Florence. Science historique et sociologie chez Georg Simmel. Montreal, Sociologies et societies, v. 2, n. 44, 2012.

LASH, Scott. Another modernity, a different rationality. Oxford, UK; Malden, Mass: Blackwell, 1999.

Lebenssoziologie: Georg Simmel in the information age [Online]. London, Theory, Culture \& Society, v. 22, n. 3, 2005.

Life (Vitalism). London, Theory, Culture \& Society, v. 23, n. 2, 2006.

LEVINE, Donald. Revisitando Georg Simmel. Rio de Janeiro, Sociologia \& Antropologia, v. 1, n. 1, 2015.

LÖWY, Michael. Ideologias e ciência social: elementos para uma analise marxista. 16. ed. São Paulo: Cortez Editora, 2003.

NETTO, Michel Nicolau. O uso da cultura no Romantismo alemão. Brasília, Arquivo do CMD, v. 2, n. 1, 2014. 
PYYTNIEN, Olli. Life, Death and Individuation: Simmel on the Problem of Life Itself. London, Theory, Culture and Society, v. 29, n. 7-8, 2012.

REIS, José Carlos. Wilhelm Dilthey e a autonomia das ciências históricosociais. Londrina, PR: Eduel, 2003.

SAIEDI, Nader. Simmel's epistemic road to multidimensionality. The Social Science Jornal, v. 24, n. 2, 1987.

SANTOS, Boaventura de Souza. Um discurso sobre as ciências na transição para uma ciência pós-moderna. São Paulo, Estudos avançados, v. 2, n. 2, 1988.

SCOCUGLIA, Jovanka B. C.. A hermenêutica de Wilheim Dilthey e a reflexão epistemológica nas ciências humanas contemporâneas. Brasília, Sociedade e Estado, v. 17, n. 2, 2002.

SELL, Carlos E.. Sociologia clássica: Durkheim, Weber, Marx. 2.ed. Itajaí: Univali: Editora da FURB, 2010.

SIMMEL, Georg. The conflict of modern culture. In: FEATHERSTONE, Mike \& FRISBY, David (Orgs). Simmel on culture: selected writings. London; Thousand Oaks, Calif.: Sage Publications, 1997a.

. The crisis of culture. In: FEATHERSTONE, Mike \& FRISBY,David (orgs). Simmel on culture: selected writings. Londres; Thousand Oaks, Calif.: Sage Publications, 1997b.

- O conceito e a tragédia da cultura. In: SOUZA, Jessé \& ÖELZE, Berthold (orgs.) Simmel e a Modernidade. Brasília: Unb, 1998.

. Individualism [Online]. Londres, Theory, Culture and Society, v. 24, n. 7-8, 2007a.

Kant and Goethe on the History of the Modern Weltanschauung [Online]. Londres, Theory, Culture and Society, v. 24, n. 6, 2007b.

Questões fundamentais da sociologia: indivíduo e sociedade. Rio de Janeiro, RJ: Jorge Zahar, 2006.

SKINNER, Quentin. As fundações do pensamento político moderno. São Paulo: Companhia das Letras, 1996.

VANDENBERGHE, Frédéric. La double dualité comme principe d'unité de la pensée simmelienne [Online]. Bielefeld: Simmel Newsletter, v. 9, n. 2, 1999. Disponivel em:

http:/ / www.georg-simmelgesellschaft.org/00_simmel/simstudscroll.htm. Acesso em: 17/11/2016.

As sociologias de Georg Simmel. Belém, PA; Bauru, SP: EDUPFA: EDUSC, 2005. 
Construção e crítica na nova sociologia francesa. Brasília, Sociedade e Estado, v. 21, n. 2, 2006.

WAIZBORT, Leopoldo. As aventuras de Georg Simmel. São Paulo: USP, Editora 34, 2000.

O mal-entendido da democracia. Sergio Buarque de Hollanda, Raízes do Brasil, 1936. São Paulo, Revista Brasileira de Ciências Sociais, v. 26, n. 76, 2011a.

Wilhelm Dilthey em novas traduções. Rio de Janeiro, Sociologia \& Antropologia, v. 1, n. 2, 2011 b. 